Faktor Risiko Kejadian Persalinan Sectio Caesarea di Rumah Sakit Djafar Harun

\title{
Risk Factors of Sectio Caesarea Delivery at Djafar Harun Hospital
}

\author{
Samsi Burhan, Agusrinal, Ika Sartika, Asmurti \\ Universitas Nahdlatul Ulama Sulawesi Tenggara \\ (muhammadnizam7777@gmail.com, 082394833880)
}

\begin{abstract}
ABSTRAK
Jumlah ibu bersalin dengan persalinan sectio caesarae di BLUD R.S H.M Djafar Harun Kolaka Utara tahun 2015 sebanyak 254 orang, kemudian meningkat di tahun 2016 sebanyak 521 orang.Tujuan penelitian ini adalah untuk menganalisis faktor risiko kejadian persalinan sectio caesarea di RumahSakit H.M Djafar Harun, Kolaka Utara. Jenis penelitian adalah penelitian observasional analitik dengan pendekatan studi kasus kontrol. Populasi penelitian sebanyak 68 dengan sampel 136 orang menggunakan teknik accidental sampling. Analisis data menggunakan uji Odds Ratio. Hasil analisis berdasarkan panggul sempit menunjukkan nilai $\mathrm{OR}=9,681 ; \mathrm{LL}=2,728 ; \mathrm{UL}=34,355$, serta faktor plasenta previa menunjukkan nilai $\mathrm{OR}=6,484 ; \mathrm{LL}=0,759$; $\mathrm{UL}=55,385$. Kesimpulannya, panggul sempit merupakan faktor risiko yang kuat dan plasenta previa merupakan bukan faktor risiko yang kuat kejadian persalinan sectio caesarea. Diharapkan kepada pihak rumah sakit untuk mengupayakan identifikasi kehamilan berisiko tinggi, komplikasi atau kelainan kehamilan agar dapat diketahui secara dini sehingga mampu menangani lebih optimal masalah komplikasi pada saat persalinan.
\end{abstract}

Kata Kunci: Sectio caesarea, panggul sempit, plasenta previa

\section{ABSTRACT}

The number of mothers giving birth with sectio caesarae delivery at BLUD R.S H.M Djafar Harun North Kolaka in 2015 was 254 people, then increased in 2016 to 521 people. The purpose of this study was to analyze the risk factors for the incidence of Sectio Caesarea delivery at H.M Djafar Harun Hospital, North Kolaka. This type of research is an analytic observational study with a case-control study approach. The study population was 68 with a sample of 136 people using the Accidental Sampling Technique. Data analysis using the Odds Ratio test. The results of the risk analysis based on narrow pelvic factors showed the value of $O R=9,681 ; L L=2,728 ; U L=34,355$, and then placenta previa factor showed the value of $O R=6,484 ; L L=$ 0,759; UL=55,385. In conclusion, narrow pelvis is a strong risk factor and placenta previa is not a strong risk factor for Sectio Caesarea delivery. It is hoped that the hospital will seek to identify high-risk pregnancies, complications or pregnancy abnormalities so that they can be detected early so that they are able to more optimally handle complications during childbirth.

Keywords: Sectio caesarea, narrow pelvis, placenta previa

Article Info:
Received: 30 Maret 2021 | Revised form: 20 April 2021 | Accepted: 19 Juni 2021 | Published online: 30 Juni 2021 


\section{PENDAHULUAN}

Kematian ibu merupakan salah satu masalah kesehatan yang menjadi fokus SDGs (Sustainable Development Goals). Kematian ibu adalah salah satu goals yang tedapat pada salah satu tujuan dari 17 Tujuan SDGs yaitu Sistem Kesehatan Nasional. Goals ke 3 berisi target untuk menurunkan angka kematian ibu hingga kurang dari 70 per 100.000 kelahiran hidup pada tahun 2030, menurunkan kematian bayi dan balita, mengurangi 1/3 kematian prematur akibat penyakit infeksi melalui pencegahan dan perawatan, serta memajukan kesehatan dan kesejahteraan mental/psikis dan menjamin akses semesta terhadap pelayanan kesehatan seksual dan reproduksi, termasuk KB (Keluarga Berencana), informasi dan pendidikan, serta intergrasi kesehatan reproduksi ke dalam strategi dan progam nasional. ${ }^{1}$

Kehamilan risiko tinggi adalah keadaan kehamilan dengan yang menimbulkan dampak serius yakni kecatatan atau ancaman kematian pada janin. Pada kehamilan risiko tinggi diperlukan pelayanan khusus bagi ibu dan janin. Ganggunan kehamilan yang dialami ibu secara tidak langsung mengancam keselamatan kehidupan ibu dan janin. ${ }^{2}$ Adapun solusi yang selalu ditawarkan petugas medis ketika ibu memuliki kehamilan berisiko tinggi saat akan melahirkan adalah Sectio Caesarea (SC).

Persalinan Sectio Caesarea merupakan salah satu tindakan medis yang dipilih jika persalinan normal tidak bisa dilakukan. Tindakan ini diambil untuk menghindari komplikasi saat persalinan. Adapun SC yaitu suatu cara melahirkan janin pada dinding uterus pada dinding depan abdomen. Saat ini Sectio Caesarea sangat aman berkat kemajuan teknologi mulai dari antibiotik, anestesi ataupun teknik operasinya mendekati sempurna, sehingga probabilitasnya cukup besar persalinan melakukan operasi ini tanpa adanya gejala medis. ${ }^{3}$

Angka persalian Sectio caeesarea semakin bertambah tiap tahunnya di seluruh dunia, terutama baik pada negara-negara ekonomi menengah ke atas. Data yang didaptkan dari Rumah Sakit dr. Moewardi ditemukan berbagai faktor penyebab dilakukannya persalinan Sectio Caesarea yakni $40 \%$ ketuban pecah dini, 26\% Chepalopelvik Disproportion (CPD) atau DKP (Disproporsi Kepala Panggul), 20\% kelainan letak janin dan $14 \%$ ancaman gawat janin. Sementara angka kejadian Sectio Caesarea karena faktor ketuban pecah dini di Rumah Sakit Umum Daerah Dr. Soehadi Prijonegoro Sragen tahun 2012 sebesar 20,75\% dari 65,67\% angka kelahiran Sectio Caesarea. ${ }^{4}$

Hasil Survei Demografi dan Kesehatan Indonesia (SDKI) tahun 2012, angka kejadian Sectio Caesarea sebesar 22,8\% dari seluruh persalinan. Menurut hasil survey kesehatan bahwa 9,8\% Sectio Caesarea dengan proporsi tertinggi ditemukan di DKI Jakarta (19,9\%) dan paling rendah ditemukan di Sulawesi Tenggara $(3,3 \%){ }^{5}$

Berdasarkan hasil penelitian yang dilakukan oleh Novianti, terkait determinan persalinan Sectio Caesarea di Indonesia menyebutkan bahwa terdapat beberapa faktor yang mempengaruhi seorang ibu melakukan section caesarea diantaranya, yaitu faktor sosiodemografi, kepemilikan jaminan kesehatan, usia kelahiran, jumlah janin, umur ibu, tinggi badan ibu, penyakit 
penyulit persalinan, komplikasi kehamilan, komplikasi persalinan, paritas dan Antenatal Care (ANC) $\mathrm{K}^{6}{ }^{6}$

Berdasarkan hasil studi pendahuluan yang telah dilakukan oleh peneliti di BLUD R.S H.M Djafar Harun Kolaka Utara dimana jumlah ibu bersalin di Rumah sakit H.M Djafar harun pada tahun 2015 sebanyak 464 ibu bersalin dengan persalinan Sectio Caesarea 254 orang(18,23\%), namun pada tahun 2016 terjadi peningkatan jumlah ibu bersalin sebanyak 750 ibu dari $750 \mathrm{ibu}$ bersalin sebanyak 521 orang yang melakukan persalinan Sectio Caesarea dan pada tahun 2017 (Januari - Juni) jumlah persalinan 523 ibu bersalin dan dari $523 \mathrm{ibu}$ bersalin terdapat sebanyak 160 ibu bersalin. Tujuan penelitian ini adalah untuk menganalisis faktor risiko terhadap terjadinya persalinan Sectio Caesarea di BLUD Rumah Sakit H.M Djafar harun Kolaka Utara.

\section{BAHAN DAN METODE}

Jenis penelitian yaitu observasional analitik dengan rancangan studi kasus kontrol (Case Control Study). Penelitian dimulai dari identifikasi terhadap kasus persalinan Sectio Caesarea) lalu dilihat secara retrospektif ada atau tidak adanya faktor risiko yang diduga berperan. Sebagai kontrol dipilih subyek yang berasal dari populasi yang sama yakni yang melakukan persalinan normal. Lokasi penelitian dilaksanakan di BLUD Rumah Sakit H.M Djafar Harun Kolaka Utara. Populasi penelitian adalah semua ibu hamil baik yang datang sendiri maupun rujukan yang melahirkan di BLUD Rumah Sakit H.M Djafar Harun Kolaka Utara baik secara normal maupun dengan Sectio Caesarea pada tahun 2017. Jumlah persalinan yang ada sebanyak 523 dengan 160 tindakan persalinan Sectio Caesarea pada 2017. Unit observasi adalah status ibu yang melahirkan di rumah sakit tersebut (medical record). Unit analisis adalah keseluruhan kejadian persalinan dan semua faktor risiko serta karakteristik umum yang berhubungan. Sampel penelitian terbagi atas sampel kasus dan sampel kontrol dengan perbandingan 1:1, dimana sampel kasus berjumlah 68, sehingga sampel kontrol yang diambil juga 68 ibu. Teknik pengambilan sampel menggunakan teknik accidental sampling. Analisis data menggunakan uji Odds Ratio dengan Confidence Interval sebesar $95 \%$.

\section{HASIL}

Karakteristik responden penelitian ini terdiri dari usia, paritas, pendidikan, dan pekerjaan yang dapat dilihat pada Tabel 1. Usia ibu yang melahirkan paling banyak yang berasal dari kelompok usia 25-29 tahun yakni sebesar 32,3\%. Tabel 1 juga menunjukkan karakteristik responden berdasarkan paritas ibu yang melahirkan paling banyak yang belum pernah melahirkan sebelumnya yaitu sebanyak 47 responden $(34,6 \%)$ dan paling sedikit yang jumlah paritasnya 6 sebesar $0,7 \%$. Dari segi pendidikan ibu menunjukkan bahwa jenjang pendidikan yang paling banyak ditempuh oleh ibu yang melahirkan sebagai sampel penelitian pada kasus adalah SMA sebesar 51,5\% dan pada kontrol dengan persentase $39,7 \%$. Sedangkan tingkat pendidikan yang terendah pada sampel kasus adalah S2 sebesar $1,5 \%$. Adapun pada sampel penelitian kelompok 
kontrol yakni S2 masing-masing sebesar 1,5\%. Sementara jika dilihat dari karakteristik pekerjaan ibu dimana yang melahirkan secara sectio caesarea sebanyak $77,9 \%$ pekerjaannya adalah ibu rumah tangga, sedangkan melahirkan normal persentasinya $80,9 \%$. Persentase yang terendah yakni ibu yang bekerja di BUMN hanya $0,7 \%$.

Tabel 1. Distribusi Frekuensi Berdasarkan Karakteristik Responden di Rumah Sakit Djafar Harun

\begin{tabular}{|c|c|c|c|c|c|c|}
\hline \multirow{2}{*}{$\begin{array}{c}\text { Jenis } \\
\text { Kelamin }\end{array}$} & \multicolumn{2}{|c|}{ Kasus } & \multicolumn{2}{|c|}{ Kontrol } & \multirow{2}{*}{$\mathbf{n}$} & \multirow{2}{*}{$\%$} \\
\hline & $\mathbf{n}$ & $\%$ & $\mathbf{n}$ & $\%$ & & \\
\hline \multicolumn{7}{|c|}{ Umur (tahun) } \\
\hline $16-19$ & 4 & 5,9 & 4 & 5,9 & 8 & 5,9 \\
\hline $20-24$ & 8 & 11,8 & 8 & 11,8 & 16 & 11,8 \\
\hline $25-29$ & 22 & 32,3 & 22 & 32,3 & 44 & 32,3 \\
\hline $30-34$ & 20 & 29,4 & 20 & 29,4 & 40 & 29,4 \\
\hline $35-39$ & 11 & 16,2 & 11 & 16,2 & 22 & 16,2 \\
\hline $40-44$ & 3 & 4,4 & 3 & 4,4 & 6 & 4,4 \\
\hline \multicolumn{7}{|l|}{ Paritas } \\
\hline 0 & 25 & 36,8 & 22 & 32,4 & 47 & 34,6 \\
\hline 1 & 23 & 33,8 & 19 & 27,9 & 42 & 30,9 \\
\hline 2 & 12 & 17,6 & 16 & 23,5 & 28 & 20,6 \\
\hline 3 & 5 & 7,4 & 6 & 8,8 & 11 & 8,1 \\
\hline 4 & 2 & 2,9 & 3 & 4,4 & 5 & 3,7 \\
\hline 5 & 1 & 1,5 & 1 & 1,5 & 2 & 1,5 \\
\hline 6 & 0 & 0 & 1 & 1,5 & 1 & 0,7 \\
\hline
\end{tabular}

\section{Pendidikan}

\begin{tabular}{|c|c|c|c|c|c|c|}
\hline $\begin{array}{l}\text { Tidak } \\
\text { Sekolah }\end{array}$ & 0 & 0 & 1 & 1,5 & 1 & 0,7 \\
\hline SD & 4 & 5,9 & 4 & 5,9 & 8 & 5,9 \\
\hline SMP & 2 & 2,9 & 5 & 7,4 & 7 & 5,1 \\
\hline SMA & 35 & 51,5 & 27 & 39,7 & 62 & 45,6 \\
\hline Diploma & 8 & 11,8 & 13 & 19,1 & 21 & 15,4 \\
\hline $\mathrm{S} 1$ & 18 & 26,5 & 17 & 25 & 35 & 25,7 \\
\hline S2 & 1 & 1,5 & 1 & 1,5 & 2 & 1,5 \\
\hline
\end{tabular}

\begin{tabular}{lrrrrrr}
\hline Pekerjaan & & & & & & \\
\hline IRT & 53 & 77,9 & 55 & 80,9 & 108 & 79,4 \\
PNS & 6 & 8,8 & 7 & 10,3 & 13 & 9,6 \\
Swasta & 8 & 11,8 & 6 & 8,8 & 14 & 10,3 \\
BUMN & 1 & 1,5 & 0 & 0 & 1 & 0,7 \\
\hline Total & $\mathbf{6 8}$ & $\mathbf{1 0 0}$ & $\mathbf{6 8}$ & $\mathbf{1 0 0}$ & $\mathbf{1 3 6}$ & $\mathbf{1 0 0}$ \\
\hline
\end{tabular}

Sumber: Data Primer, 2020

Pada Tabel 2, Ibu yang melahirkan di BLUD R.S H.M Djafar Harun Kolaka Utara dan mengalami tindakan persalinan Sectio Caesarea, yang didiagnosis mengalami panggul sempit sebesar 30,9\% (21 ibu inpartu) dan yang tidak mengalami panggul sempit sebanyak $69,1 \%$ (47 ibu inpartu). Sedangkan ibu yang melahirkan normal dan di diagnosis berisiko tinggi sebanyak 3 $(4,4 \%)$ orang dan yang berisiko rendah sebanyak $65(95,6 \%)$ orang.Hasil analisis risiko kejadian persalinan Sectio Caesarea berdasarkan faktor panggul sempit, menunjukkan bahwa nilai $\mathrm{OR}=$ 9,681. Hasil uji kebermaknaan nilai OR tersebut, dengan Confidence Interval sebesar 95\% diperoleh nilai Lower Limit (LL) 2,728 sebesar dan Upper Limit (UL) sebesar 34,355. Hal inimenunjukkan bahwa variabel panggul sempit merupakan faktor risiko kejadian persalinan Sectio Caesarea $(\mathrm{OR}>1)$.Dengan demikian hipotesis nol (Ho) ditolak, berarti panggul sempit merupakan faktor risiko yang kuat kejadian persalinan Sectio Caesarea.

Ibu yang melahirkan di BLUD R.S H.M Djafar Harun Kolaka Utara dan mengalami persalinan Sectio Caesarea, dengan diagnosis adanya plasenta yang menghalangi jalan lahir yakni $6(8,8 \%)$ orang. Sedangkan yang tidak berisiko tinggi $62(91,2 \%)$ orang. Ibu yang melahirkan secara normal dengan adanya plasenta previa sebanyak $1(1,5 \%)$ orang dan yang berisiko rendah sebanyak $67(98,5 \%)$ orang. Hasil analisis faktor risiko kejadian persalinan Sectio Caesarea berdasarkan faktor plasenta previa menunjukkan nilai $\mathrm{OR}=6,484$. Hal ini berarti variabel plasenta previa merupakan faktor risiko kejadian persalinan Sectio Caesarea (OR>1). Hasil uji kebermaknaan nilai OR tersebut, dengan Confidence Interval sebesar 95\% diperoleh nilai Lower Limit (LL) 
sebesar dan Upper Limit (UL) sebesar 0,759 dan 55,385, menunjukkan bahwa nilai OR yang diperoleh tidak bermakna (meliputi nilai 1). Hal ini berarti bahwa plasenta previa bukan merupakan faktor risiko yang kuat terhadap kejadian persalinan Sectio Caesarea.

Tabel 2. Risiko Kejadian Persalinan Sectio Caesarea Berdasarkan Faktor Panggul Sempit dan Plasenta Previa di BLUD R.S H.M Djafar Harun Kolaka Utara

\begin{tabular}{|c|c|c|c|c|c|c|c|}
\hline \multirow{3}{*}{ Variabel } & \multicolumn{4}{|c|}{$\begin{array}{c}\text { Kejadian Persalinan Sectio } \\
\text { Caesarea }\end{array}$} & \multirow{3}{*}{$\mathbf{N}$} & \multirow{3}{*}{$\%$} & \multirow{3}{*}{$\mathrm{CI}=95 \%$} \\
\hline & \multicolumn{2}{|c|}{ Kasus } & \multicolumn{2}{|c|}{ Kontrol } & & & \\
\hline & $\mathbf{n}$ & $\%$ & $\mathbf{n}$ & $\%$ & & & \\
\hline Panggul Sempit & & & & & & & $\mathrm{OR}=9.681$ \\
\hline Risiko Tinggi & 21 & 30,9 & 3 & 4,4 & 24 & 17,6 & $\begin{array}{l}U K=9,081 \\
L L=2,728\end{array}$ \\
\hline Risiko Rendah & 47 & 69,1 & 65 & 95,6 & 112 & 82,4 & $\begin{array}{l}\mathrm{LL}=2, / 28 \\
\mathrm{UL}=34,355\end{array}$ \\
\hline Jumlah & 68 & 100,0 & 68 & 100,0 & 136 & 100,0 & \\
\hline Plasenta Previa & & & & & & & \\
\hline Risiko Tinggi & 6 & 8,8 & 1 & 1,5 & 7 & 5,1 & $\begin{array}{r}O K=6,484 \\
\end{array}$ \\
\hline Risiko Rendah & 62 & 91,2 & 67 & 98,5 & 129 & 94,9 & $\begin{array}{r}\mathrm{LL}=0, / 39 \\
\mathrm{UL}=55385\end{array}$ \\
\hline Jumlah & 68 & 100,0 & 68 & 100,0 & 136 & 100,0 & \\
\hline
\end{tabular}

Sumber : Data Primer, 2020

\section{PEMBAHASAN}

DKP (Disproporsi Kepala Panggul) atau CPD adalah gejala mutlak mengambil tindakan SC. Pada DKP persalinan secara pervaginam tidak memungkinkan, dikarenakan panggul ibu yang sempitnya, janin berukuran terlalu besar atau kombinasi keduanya, sehingga jika dipaksakan dapat membahayakan ibu dan janin seperti menimbulkan komplikasi hingga kematian. ${ }^{7}$

Panggul sempit merupakan salah satu faktor biomedis yang mempunyai prevalensi yang tinggi terhadap persalinan sectio pada penelitian ini. Panggul sempit adalah kelainan patologis, dimana terdapat kelainan struktur baik mikroskopik maupun makroskopik berbagai organ dan jaringan yang dapat disebabkan oleh penyakit atau proses lainnya. Panggul sempit secara sederhana berarti bayi yang dilahirkan tidak dapat melewati pelvik (panggul) ibu secara aman atau besar janin tidak sesuai dengan panggul ibu. Panggul sempit merupakan faktor risiko yang kuat terhadap kejadian persalinan Sectio Caesarea.

Persalinan dengan DKP jika dilakukan tanpa tindakan yang akurat, akan mengancam keselamatan ibu dan janin. Bahaya pada ibu dantaranya; Pertama, kelahiran lama yang disertai ketuban pecah pada pembukaan kecil penyebab kekurangan cairan (dehidrasi) serta asidosis, dan infeksi intrapartum. Kedua, dengan his yang kuat, sedang kemajuan janin dalam jalan lahir tertahan, dan bertambah parah jika tidak segera diambil tindakan untuk mengurangi regangan, akan muncul ruptur uteri. Ketiga, dengan persalinan tidak maju karena Disporsi Sefalopelvik, jalan lahir mengalami tekanan yang lama antara kepala janin dan tulang panggul. Hal tersebut mengakibatkan sirkulasi terganggu yang kelak menimbulkan iskemia serta nekrosis pada tempat tersebut. 
Hasil penelitian menunjukkan bahwa panggul sempit merupakan faktor risiko kejadian Sectio Caesarea di Rumah Sakit Djafar Harun, dengan nilai $\mathrm{OR}=9,681$ yang berarti wanita dengan panggul sempit 9,681 kali lebih berisiko melakukan Sectio Caesarea dibanding yang tidak memiliki panggul sempit. Penelitian ini didukung oleh hasil penelitian Astuti di RSUD Prabumulih serta penelitian Wulandari di RS dr. Soehadi Prijonagoro Sragen, meskipun faktor DKP terhadap tindakan Sectio Caesaria pada penelitian ini lebih rendah risikonya bila dibandingkan dengan besarnya risiko yang didapatkan Wulandari yakni 30,412 kali lebih beresiko SC dibandingkan dengan persalinan normal. ${ }^{8,9}$

Plasenta previa terjadi karena adanya kelainan patologis, dimana plasenta posisinya abnormal yaitu pada segmen bawah rahim sehingga menutupi sebagian atau seluruhnya jalan lahir. Pada keadaan normal plasenta posisinya terdapat di bagian atas uterus. Pada Sectio Caesarea dilakukan sayatan didinding uterus akan menyebabkan perubahan atropi pada desidua dan berkurangnya vaskularisasi, kedua hal ini akan mengakibatkan aliran darah ke janin tidak cukup dan menyebabkan plasenta tempat yang lebih luas dan endometrium yang masih baik untuk berimplantasi yaitu disegmen bawah rahim sehingga dapat menutupi sebagian atau seluruh ostium uteri internum. Hal ini akan meningkat pada wanita yang sudah melakukan 2 kali atau lebih Sectio Caesarea dimana jaringan parutnya sudah lebih banyak demikian juga kecacatan pada fundus uteri atau dinding rahimnya secara otomatis lebih luas. ${ }^{10}$
Hasil analisis risiko terhadap kejadian persalinan Sectio Caesarea berdasarkan faktor plasenta previa yang menunjukkan bahwa plasenta previa bukan merupakan faktor risiko yang kuat. Hal ini dapat dijelaskan bahwa penanganan persalinan secara Sectio Caesarea bergantung pada derajat plasenta tersebut, dimana apabila diagnosis plasenta letak rendah atau plasenta previa marginalis maka masih dapat dilakukan persalinan normal dengan cara pemecahan selaput ketuban.

Hasil analisis faktor risiko kejadian persalinan Sectio Caesarea berdasarkan faktor plasenta previa menunjukkan bahwa nilai OR = 6,484. Ini berarti variabel plasenta previa merupakan faktor risiko kejadian persalinan Sectio Caesarea (OR $>1)$. Menurut penelitian Aprina (2016) mengenai faktor-faktor yang berhubungan dengan persalinan Sectio Caesarea di RSUD DR.H Abdul Moeloek Provinsi Lampung, dari hasil penelitian didapatkan bahwa responden dengan Plasenta previa memiliki peluang 3,30 kali untuk kejadian dilakukan Sectio Caesarea dibandingkan dengan yang tidak plasenta previa. Pada keadaan normal plasenta umumnya terletak di korpus uteri bagian depan atau belakang agak ke arah fundus uteri. Dalam keadaan plasenta previa, ibu hamil memiliki indikasi Sectio Caesarea. Ini disebabkan karena keadaan plasenta yang tidak normal. Hal yang dapat disarankan dari penelitian ini adalah diperlukan adanya upaya untuk mengidentifikasi kehamilan berisiko tinggi, komplikasi atau kelainan kehamilan agar dapat diketahui lebih awal sehingga mampu menangani lebih optimal masalah komplikasi pada saat 
persalinan. ${ }^{11}$

\section{KESIMPULAN DAN SARAN}

Kesimpulan dalam penelitian ini adalah panggul sempit merupakan faktor risiko yang kuat kejadian persalinan Sectio Caesarea, dan plasenta previa bukan merupakan faktor risiko yang kuat terhadap kejadian persalinan Sectio Caesarea di BLUD R.S H.M Djafar Harun Kolaka Utara.Hal yang dapat disarankan dari penelitian ini adalah perlu adanya upaya untuk mengidentifikasi kehamilan berisiko tinggi, komplikasi atau kelainan kehamilan agar dapat diketahui secara dini sehingga mampu menangani lebih optimal masalah komplikasi pada saat persalinan.

\section{DAFTAR PUSTAKA}

1. Kementerian Kesehatan RI. Kesehatan dalam Rangka Sustainable Development Goals (SDGs). Jakarta; 2015.

2. Astuti S. Buku Ajar Kebidanan: Asuhan Ibu dalam Masa Kehamilan. Yogyakarta: Erlangga; 2017.

3. Mochtar R. Sinopsis Obstetri Fisiologi Obstetri Patologi. 1 ed. Jakarta: EGC; 2012.

4. Sumelung V, Kundre R, Karundeng M. Faktor-Faktor Yang BerperanMeningkatnya Angka KejadianSectio Caesarea Di Rumah Sakit Umum Daerah Liun Kendage Tahuna. J Keperawatan. 2014;2(1):1-7.

5. Riskesdas. Riset Kesehatan Dasar 2013. Jakarta: Badan Penelitian dan Pengembangan Kesehatan; 2013.

6. Sihombing NM, Saptarini I, Putri DSK. Determinan persalinan Sectio Caesarea di
Indonesia (analisis lanjut data Riskesdas 2013). Indones J Reprod Health. 2017;8(1):63-73.

7. Cunningham dkk. Obstetri William. Jakarta: Buku Kedokteran EGC; 2010.

8. Astuti DW. Kejadian Sectio Caesarea Ditinjau dari Disproporsi Kepala Panggul dan Plasenta Previa. Cendekia Med. 2018;3(1):15.

9. Wulandari Y. Hubungan Beberapa Faktor Medis Dengan Jenis Persalinan Di RSUD Dr. Soehadi Prijonagoro SragenTahun 2011. [Surakarta]: Universitas Muhammadiyah Surakarta; 2013.

10. Trianingsih I. Hubungan Riwayat Sectio Caesarea Dan Riwayat Placenta Previa Pada Kehamilan Sebelumnya Dengan Kejadian Placenta Previa. J Kesehat Metro Sai Wawai. 2019;6(2):65-68.

11. Aprina A, Puri A. Faktor-faktor yang Berhubungan dengan Persalinan Sectio Caesarea di RSUD dr. H. Abdul Moeloek Provinsi Lampung. J Kesehat. 2016;7(1):9096. 